\title{
The Quality of Learning in The Perspective of Learning as A System
}

\author{
Anik Ghufron \\ Education Technology Study Program \\ Faculty of Education Science \\ Universitas Negeri Yogyakarta, Indonesia \\ anikghufron@uny.ac.id
}

\author{
Deni Hardiyanto \\ Education Technology Study Program \\ Faculty of Education Science \\ Universitas Negeri Yogyakarta, Indonesia
}

\begin{abstract}
This study aims to examine and simultaneously find the concept of quality learning in the perspective of learning as a system. This research was conducted in the background of the inequality and confusion of learning quality concept. This research uses qualitative approach with "grounded theory" method. The research subjects as data sources are the doctorate degree experts from the Education Management, Education Policy, Education technology, Nonformal education, Guidance and counselling, Special education, and Elementary School Teacher Education Faculty of Education Universitas Negeri Yogyakarta as many as 10 people. They were chosen because of their expertise in the field of learning. Technique of collecting data by using interview and observation. Data analysis techniques are inductive. The results concluded; (1) the quality of learning is defined as the degree of learning excellence, which emphasizes aspects of the process or outcome or both. Which meanings are used strongly influenced by the interests of its users, (2) every meaning of quality of learning used by someone has their own characteristics, (3) aspects related to learning quality dimension as the system has their own qualification and criteria. The fulfillment of qualifications and criteria of these aspects affect the quality of learning as a system.
\end{abstract}

Keyword—quality of learning, learning as a system

\section{INTRODUCTION}

The concept of "quality of learning" from day to day is always interesting to study. This happens because the problem of quality of learning is always related to the interests of the people who have an interest in learning activities. No one is hoping to get a learning service that is not qualified.

The quality of learning is defined by experts in various perspectives. For example, the quality of learning is the degree of excellence of the process of organizing learning in an educational unit, the quality of learning is a measure of the success of learning activities, the quality of learning is always related to the performance of learning, the quality of learning associated with the fulfillment of items listed in the standard process of learning version of National Education Standards Agency (BSNP). Quality of instruction has not been directly measured in many accountability systems because few assessment tools exist that have the potential to directly measure the quality of classroom practice on a large-scale basis [1].

We agree to use a reference to the quality of learning advanced by the expert, if the quality concept of learning reflects the quality of learning. Instead, we will reject the concept of the quality of learning that does not really describe the quality of learning.

The meaning of quality can be studied in two points of view, namely etymology and epistemology. Etymologically, quality has the equivalent of "degree". In Indonesian, quality means "ukuran", or "taraf atau derajat" [2]. Therefore, if one regards a good quality book then the person wants to say that the book has a high degree of content (substance) and the procedures of exposure.

Epistemologically, quality has many meanings as much as the expert who develops the meaning of quality. The meaning of quality is strongly influenced by the point of view of the developers. For example, quality means the degree of excellence of a product or the work, both in the form of goods and services [3].

In the view of the researcher, although the meanings of quality vary but the focus of the study remains to the "degree, excellence, and significance" of an object or activity. Quality is always related to the word "superior, degree, and benefit" of an activity or object.

What about the meaning of the quality of learning? By using the meanings above, the quality of learning can be defined as the degree or level of excellence of all aspects of learning. Instructional quality refers not to any measure of actions taken in the classroom (such as observations of class sessions), but rather to the full set of classroom interactions that affect student learning, including the ability of the instructor, the quality of instruction delivered by that instructor (including curriculum, teaching methods, etc.), and other classroom-level factors such as peer effects [4].

The concept of the quality of learning cannot be separated from the expert's perspective on the learning activities itself. If at this time arise a discourse that the 
meaning of learning is categorized into three clusters, namely learning as a purposeful activity, communication process, and a system, then the concept of quality learning will be influenced by the characteristics of the meaning of learning.

Learning as an activity is an activity pursued by educators to deliver learners towards a desired goal. In general, the stages of learning activities in this perspective are the opening, core, and closing activities. If we use this point of view, then the quality of learning will contain the three stages of learning.

Learning as a process of communication is a learning activity in the form of a series of communication process, which contains aspects of; communicators, messages, media, message recipients, and feedback. If we use this angle of the field then the quality of learning will involve aspects related to communicators, messages, media, and recipients of the message, and feedback.

Learning as a system is a series of activities containing aspects; Input, process, and output. If we use this point of view then the quality of learning will include aspects related to inputs, processes, and outcomes.

Related to the study about the concept of quality learning from the perspective of learning as a system then the quality of learning cannot be separated from the forming aspects of learning activities as a system. A minimum system will load input, process, and output. Thus, the area of study of the quality of learning in the learning perspective as a system will contain; Input (raw, environmental, and instrumental), processes, and output (outputs and outcomes).

With this understanding the meaning of the quality of learning covers all aspects of learning. Even if it is related to the concept of integrated quality management, learning is said to be in good quality if there is a win-win situation, that is, all those involved in learning activities are happy, treated fairly, and well served [5]. In this context, the aspect of satisfaction becomes one of the criteria of good quality in learning activity. On the other hand, there is a defining quality of education as the ability of schools in the management of operational and efficient against the components associated with school, so as to generate added value to the component according to norms or standards applicable.

Based on the description above of the quality of learning can be defined as a code that describes the learning process takes place in a superior, adequate, and provide benefits for the development of all potential of learners. The quality of learning is not only seen from the learning outcomes, but also on the learning process. Even on the input dimension.

The existence of various opinions about the quality of learning that developed today is very interesting to be followed and discussed. This is because the concept of the quality of learning that is developed today is often used as a reference for the stakeholders in developing and improving the quality of learning.

In Indonesia, the improvement of the quality of learning is positioned as part of the four strategic issues of educational development. Therefore, the study of the concept of the quality of education needs to be done as soon as the result is significantly related to the students' learning ability. During the 1990s, a new policy hypothesis - that focusing on the quality of teaching would provide a highleverage means for improving student achievement- began to gain currency [6].

What is the conceptual of quality of learning? This question triggers the researcher to study the concept of the quality of learning in the learning perspective as a system. In more detail, some of the questions to be answered in this study include the current concept of learning quality in educational practice, learning quality characteristics, and aspects related to the dimensions of learning quality as a system.

This study aims to find out the concept of the quality of learning that develops today in the practice of education, the various characteristics of the quality of education, and aspects related to the dimensions of the quality of learning as a system. The findings of this study, is expected to be useful for the development of constructs and the concept of quality learning based on the understanding of the quality of learning that developed in the practice of education. In addition, the findings of this study can serve as a reference in improving the quality of learning.

\section{II.METHODS}

This research used qualitative approach with grounded theory method. The reason is that researchers want to develop and reconstruct theories about the quality of learning in the learning perspective as a system based on developing learning theories and praxis.

The phase of research with grounded theory method begins with searching through observation and interviews of various quality teaching practices, followed by reviewing the findings of quality learning practices with experts and education practitioners to obtain descriptions and indications about the quality of learning, then, end by doing Inductive analysis to build a new theory about the quality of learning.

This research was conducted in the Faculty of Education of Universitas Negeri Yogyakarta. The reason, in this faculty many experts with various backgrounds of the field of science, which mastering the concept of quality learning are available.

Research was conducted in six months. Beginning by preparing proposals, developing research instruments, data collection, data analysis, and preparation of research reports.

Research subjects as data sources are lecturers with 
doctoral degrees from Education Management Study Program, Education Policy, Education Technology, Nonformal education, Guidance and Counseling, Special Education, and Teacher Education of FIP UNY Elementary School consisting of 10 (ten) persons expert. They were chosen because of their expertise in the field of learning.

Data collection is carried out by the researchers themselves. By using the instrument, the researcher collects a number of required information regarding the concept of the quality of learning, characteristics, and aspects related to the learning dimension as a system. This is done, in order to understand the opinions of experts on the concept of the quality of learning in context.

Data collection techniques used in this study are interviews and documentation. Interviews are used to seek verbal information directly from the field of learning experts. Documentation is used to find various theories and research results about the concept of quality learning and various aspects related to the dimension of quality of learning as a system

Study time for six months. Beginning by preparing proposals, developing research instruments, data collection, data analysis, and preparation of research reports.

Research subjects as data sources are lecturers with doctoral degrees from Education Management Study Program, Education Policy, Education Technology, Nonformal education, Guidance and Counseling, Special Education, and Teacher Education of FIP UNY Elementary School consisting of 10 (ten) persons. They were chosen as their expertise in the field of learning.

Data collection is carried out by the researchers themselves. By using the instrument, the researcher collects a number of required information regarding the concept of the quality of learning, characteristics, and aspects related to the learning dimension as a system. This was done, in order to understand the opinions of experts on the concept of the quality of learning in context.

Data collection techniques used in this study are interviews and documentation. Interviews are used to seek verbal information directly from the field of learning experts. Documentation is used to find various theories and research results about the concept of quality learning and various aspects related to the dimension of quality of learning as a system.

Data analysis techniques used was data analysis techniques version of Miles and Huberman. This activity is done before the researcher go to the field with the intention; If there is incomplete data, it will immediately be completed, better understand the data revealed because it still fresh in the memory, and can be verified with other sources. The activity in qualitative data analysis is done interactively and lasted continuously until thoroughly, so the data is saturated. Data saturation sizes are indicated by no new data or information being retrieved[7].

\section{RESULTS AND DISCUSSION}

The results of this study contains three things or aspects, namely, the meaning of the quality of learning, characteristics of quality learning, and the dimensions of quality learning. These three aspects are described as follows.

\section{Meaning of learning quality}

The meaning of the quality of learning is translated in various ways. There is an impression, every expert has the meaning of quality of learning according to each point of view. There are opinions that highlight the quality of learning in terms of process or outcome. However, some argue that the quality of learning contains both process and results.

\section{Characteristics of learning quality}

Characteristics of the quality of learning is always related to the meaning of the quality of learning put forward by someone. Characteristics of the quality of learning based on the meaning of the quality of learning that emphasizes the aspects of the process, which is characterized by the activity of empowering the potential of learners optimally even maximal, active students both physically and mentally in the learning process to find the acquisition / fact, while the teacher participates as a facilitator, motivator, organizational, participatory, transformative, reflective, and dialogical.

Characteristics of quality learning based on the meaning of quality of learning that emphasizes the external aspects. For example, the characteristics of learning quality include achievement of goals, learning productivity, management efficiency, effectiveness, attractiveness, conducive and value-added. Characteristic of learning quality that is happy (psychological prosperity) learners, completed achievement of competence offered, good administration of learning, and appropriately used the model and learning technique, learning result increased, student behavior (attitude, cognition, skill) increase, teacher-student familiarity, fun learning atmosphere, and discipline.

Characteristics of the quality of learning based on the meaning of the quality of learning that emphasizes the aspects of input, process, and output is characterized by several indicators, namely the quality of learners, learning programs, learning ecosystems, learning institutions, teachers or facilitators of learning, active students, orderly learning process, The process of functional class management, leadership that supports improvement, will increase the motivation to learn, the teacher understand the students, the student is happy with the teacher, cooperative and collaborative learning, reflective assessment, there is feedback and available information system. Similarly, the teacher understands all students from the physical, mental, and talent aspects of interest so that it can be successfully increased and optimal, so that it benefits the society and the state. 
Dimensions of learning quality (inputs, processes, and outcomes)

In general, the quality of learning has dimensions of input, process, and output (outcome). Although most have the same opinion, there are variations on the parts that are related to the dimensions of the quality of learning. Similarly, the existence and significance of the dimensions of the quality of learning between the different experts.

Learning Input, consisting of the identity of learners, learning materials, facilities and infrastructure, teachers and education personnel, education policy, and academic quality. Description of each aspect of instructional input can be described as follows.

The identity of learners interpreted by the respondents in vary according to their respective perspectives, whether related to existence or significance in the input. There is a whole view, but there is also a partial. For example, the characteristics of learners that need to be considered is ready to accept learning and healthy in psychologically and physically. Similarly, there is a view that the characteristics of the learners are dynamic.

Quality learning materials are described by respondents in various ways, both in substance and urgency. For example, there is a view which says that quality learning materials are learning materials in accordance with student development (physical/psychological), comprehensive, futuristic, contextual, and can be transferred to learners.

Quality learning facilities and infrastructure are divided into two categories, namely hardware and software. Quality learning facilities and infrastructure must also meet the qualifications or requirements, such as completeness and facilitate learners in learning.

Teachers and qualified educational personnel related to the quality of learning are described in response to various formulations. From various views of respondents, generally more emphasize aspects of professionalism and qualifications. Others emphasize aspects of personality. Teacher quality is an important idea that is spoken in policy circles, it has taken on a variety of meaning [8].

Education policies related to the quality of learning are described by respondents. There is a comprehensive formula of education policy. However, there is a partial formulation of educational policy, which emphasizes one aspect of the quality of learning

The academic culture that supports the quality of learning is described variously by respondents. There is an opinion that academic culture is concerned with the developmental aspects of learners, the learning process, and the organization of school or class.

Learning process, consists of aspects of learning patterns, the interaction of educators with learners, and the level of participation of learners in learning. Description of each aspect as follows.
Good quality learning patterns are described by respondents with various meanings. However, in general, the pattern of learning is defined as a series of activities typical of teachers to realize the learning activities of learners. In particular, there are opinions about the meaning of learning patterns that emphasize the activity of learners' activity in learning activities. There are opinions about the meaning of learning patterns that emphasize aspects of potential development of learners. There is also an opinion about the meaning of learning patterns that emphasize aspects of the approach used.

The interaction of educators with learners as needed to shape the quality of learning varies. There are interactive models that are dialogical. There is an interpersonal interaction model. Similarly, there is a democratic interaction.

The participation of learners in learning is described by various respondents. In general, respondents stated that the participation of learners is marked the participation of learners in every learning event to realize the quality of learning. However, respondents' perspective on the shape and urgency of the participation of learners in learning for the realization of the quality of learning varies.

Product/outcome, contains two things, namely learning outcomes and graduate performance at work. These two aspects can be described as follows.

Learning outcomes are described by responses with various meanings. Nevertheless, the outline of learning outcomes is defined as behavioral changes due to learning activities, which are related to the cognitive, affective, and psychomotor domains.

The performance of graduates in the work/community is interpreted in vary by respondents. However, on the outline the performance of graduates is shown on the performance of graduates in the workplace. For example, the view that graduate performance at work is a reflection of well educated. The performance of graduates is the impact of the embodiment of values or abilities of graduates in the work.

\section{DISCUSSION}

Based on the description of the various opinions of the respondents shows that the concept of quality has a varied meaning. The diversity of the meaning of the quality of the learning presented by the respondent cannot be separated from the theoretical perspective or the academic background.

From the various meaning of the quality of learning put forward by the respondents, the meaning of the quality of learning can be categorized into three categories, namely the meaning of the quality of learning that emphasizes the process, the meaning of learning that emphasizes the results, and the meaning of learning that emphasizes the process and results.

Among the three meanings of the quality of learning, the 
authors choose the meaning of the quality of the third learning is the meaning of the quality of learning that emphasizes the process and results. Quality has to be seen in terms of relationships rather than intangible (and unattainable) goals [9]. The quality of operational learning can be interpreted as the intensity of systematic and synergistic relationship between teachers, students, curriculum and teaching materials, media, facilities, and learning systems in generating optimal learning process and learning outcomes with the demands of the curriculum. Thus, the meaning of the quality of learning that emphasizes processes and outcomes is considered inadequate.

Characteristics of the quality of learning is based and developed from the meaning of quality of learning used by experts. That is, every meaning of the quality of learning has its own characteristics. The meaning of the quality of learning that emphasizes aspects of the process is certainly different from the characteristics of the quality of learning that emphasizes the external aspects. Similarly, if the meaning of the quality of learning that emphasizes both aspects (processes and outcomes) certainly has different characteristics.

Characteristics of quality learning that emphasizes aspects of the process, among others; able to empower the potential of learners in an optimal, active learners (physically and mentally) in learning, transformative, reflective, and dialogical.

Characteristics of quality of learning that emphasizes the external aspects, among others; achievement of goals, learning productivity, effectiveness, attractiveness, conducive and value-added.

Characteristics of learning quality that emphasizes aspects of process and outcomes, among others; Qualified learners, quality learning programs, orderly in the learning process, functional classroom management process, children are happy with teachers, and learning provides benefits for others.

Of the three clusters of the characteristics above, presumably the third characteristic cluster is considered adequate. However, caution is required in applying this formula given the wide range of characteristics. On the other hands, the status of the concept of quality largely determines the management behavior it generates.

As a system, learning contains dimension of inputs, processes, and outputs. Similarly, each dimension has aspects that embody the quality of learning. The performance of the aspects of each of the dimensions of this learning system will ultimately describe the quality of learning.

Aspects related to the dimensions of input that color the quality of learning is the identity of learners, learning materials, facilities and infrastructure, teachers and education personnel, education policy, and academic culture. Aspects related to the dimensions of quality learning process, namely the pattern of learning, the interaction of educators with learners, and the level of participation of learners. Aspects related to the quality dimension of learning output, namely learning outcomes and graduate performance in the workplace.

\section{CONCLUSION}

Based on the description and discussion of the various views on the meaning of quality, characteristics, and aspects of the quality dimensions of learning as a system can be summarized as follows.

1. The quality of learning is defined as the degree of learning excellence, which emphasizes aspects of the process or outcome or both. Which meanings are used strongly influenced by the interests of its users.

2. Every meaning of the quality of learning that a person uses has their own characteristics.

3. Aspects related to the quality dimensions of learning as a system have their own qualifications and criteria. The fulfillment of qualifications and criteria of these aspects affect the quality of learning as a system.

\section{REFERENCE}

[1] Brian Junker and Yanna Weisberg, etc. 2006. Overview of the Instructional Quality Assessment: CSE Technical Report 671 tersedia pada: http://www.cse.ucle.edu/products/reports/r671.pdf

[2] Depdikbud. 1983. Kamus Umum Bahasa Indonesia. Jakarta: PN. Balai Pustaka.

[3] Sudarwan Danim. 2007. Visi Baru Manajemen Sekolah. Jakarta: Bumi Aksara.

[4] Matthew. M. Chingos. 2013. "Instructional Quality and Student Learning in Higher Education: Evidence from Developmental Algebra Courses". Diambil dari: https://www.brookings.edu/wpcontent/uploads/2016/06/11-common-college-finals-chingostechnical-paper.pdf.

[5] Ismail Pulungan. 2001. Manajemen Mutu Terpadu. Jakarta: Depdiknas: P2UT - Ditjen Dikti.

[6] Linda Darling-Hammond. 2003. "Building Instructional Quality: "Inside-Out" and "Outside-In" Perspectives on San Diego's School Reform". Research Report. Center for the Study of Teaching and Policy University of Washington.

[7] Miles, B.M \& Huberman, A.M. 1984. Qualitative Data Analysis. California: Sage Publications.

[8] Linda Darling - Hammond and Ann Lieberman. Teacher Education around the World: Changing Policies and Practice. Abingdon: Routledge.

[9] West-Burnham, John. 1997. Managing Quality in Schools. $2^{\text {nd }}$ edition. London: Pearson Education Limited.

[10] Tilaar. 1998. Beberapa Agenda Reformasi Pendidikan Nasional dalam Perspektif Abad 21. Magelang: Penerbit Tera Indonesia. 